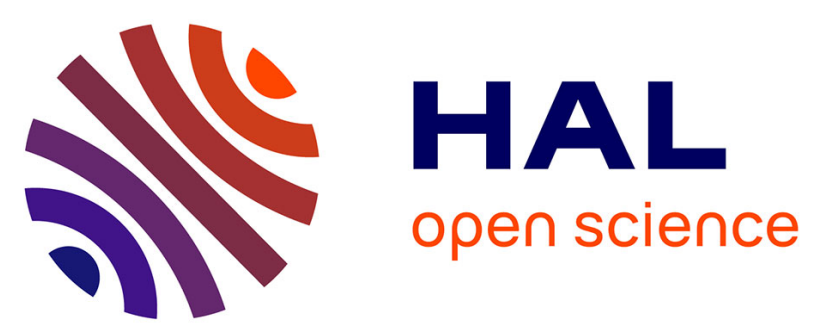

\title{
Dry Snow Analysis in Alpine Regions using RADARSAT-2 Full Polarimetry Data. Comparison With In Situ Measurements
}

Jean-Pierre Dedieu, Nikola Besic, Gabriel Vasile, J. Mathieu, Yves Durand, F. Gottardi

\section{To cite this version:}

Jean-Pierre Dedieu, Nikola Besic, Gabriel Vasile, J. Mathieu, Yves Durand, et al.. Dry Snow Analysis in Alpine Regions using RADARSAT-2 Full Polarimetry Data. Comparison With In Situ Measurements. IGARSS 2014 - IEEE International Geoscience and Remote Sensing Symposium, Jul 2014, Québec, Canada. pp.4. hal-01065809

\section{HAL Id: hal-01065809 \\ https://hal.science/hal-01065809}

Submitted on 18 Sep 2014

HAL is a multi-disciplinary open access archive for the deposit and dissemination of scientific research documents, whether they are published or not. The documents may come from teaching and research institutions in France or abroad, or from public or private research centers.
L'archive ouverte pluridisciplinaire HAL, est destinée au dépôt et à la diffusion de documents scientifiques de niveau recherche, publiés ou non, émanant des établissements d'enseignement et de recherche français ou étrangers, des laboratoires publics ou privés. 


\title{
DRY SNOW ANALYSIS IN ALPINE REGIONS USING RADARSAT-2 FULL POLARIMETRY DATA. COMPARISON WITH IN SITU MEASUREMENTS.
}

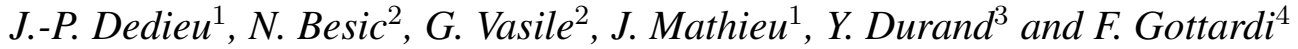 \\ ${ }^{1}$ LTHE, CNRS/Universite Grenoble-Alpes, Grenoble, France. jean.pierre.dedieu@ ujf-grenoble.fr \\ ${ }^{2}$ GIPSA-lab, CNRS /Grenoble-INP, Grenoble, France. nikola.besic @ gipsa-lab.grenoble-inp.fr \\ ${ }^{3}$ CNRM/GAME, Meteo-France/CEN, Grenoble, France. yves.durand@meteo.fr \\ ${ }^{4}$ EDF/DTG, Grenoble, France. frederic.gottardi@edf.fr
}

\begin{abstract}
In this paper we describe the benefits of RADARSAT-2 in the analysis of temporal changes in polarimetric parameters linked to the snow cover evolution during the winter season. The presented study took place over an instrumented area in the region of French Alps. The focus is set on the dry snow depth retrieval, using an original method based on principal component statistical analysis (PCA) of the polarimetric parameters values. The results obtained by this mean are compared with the network of simultaneous snow in situ measurements. The most thought-provoking result is the strong inverse correlation between the snow depth above the ice crust and the entropy, reflected through the very high coefficient of determination $R^{2}=0.8439$. In order to justify this observation, we propose an appropriate physical hypothesis.
\end{abstract}

Index Terms - dry snow, polarimetry, entropy

\section{INTRODUCTION}

Snow cover comprises a mixture of ice crystals, liquid water, and air. At temperatures below $0^{\circ}$, the proportion of liquid water is negligible and this kind of snow is called dry snow. At $\mathrm{C}$ band, estimating the location of dry snow covers and the physical properties of the snow pack remains a challenge since dry snow is a low attenuation medium and only affects the amplitude of the backscattered signal to a certain degree [1]. Due to the complexity of scattering, characterized by a wide variety of underlying media, single polarization information at $\mathrm{C}$ band is often not sufficient to distinguish between the physical properties of the dry snow volume and the ground. This is particularly true in mountainous environments with strong topographic effects.

A milestone for snow retrieval at $\mathrm{C}$ band was reached in Alpine regions with the use of the full polarimetric acquisition mode. Prompted by significant differences in backscattering

This study was carried out with the support of the SOAR/CCRS program (\#1341), Canada, the PNTS- 2009/APOA2 Program France, and the ISIS/Spot-Image contract 2013-731. The project is currently ongoing under the SOAR-EI \#5135 and PNTS 2014 \#023 programs. between the dry and the wet snow [2], a new approach for dry snow mapping was developed by Martini et al. [3]. They managed to efficiently demonstrate the capabilities of full polarimetry information, provided by the 1994 SIR-C shuttle mission, for observing dry snow covers at $\mathrm{L}$ and $\mathrm{C}$ bands, under strong topographic conditions. Operational since April 2008, the RADARSAT-2 satellite (5.4 Ghz, C band) now represents a significant and attractive technical advancement in SAR application for snow monitoring thanks to the quadpolarization acquisition mode $(\mathrm{HH}, \mathrm{HV}, \mathrm{VH}, \mathrm{VV})$, shallow incidence angle viewing capabilities and fine resolution mode. Both of latter two appear to be suitable for Alpine environments.

The principal topic of this paper concerns the advantages of RADARSAT-2 in analysis of the snow cover evolution during the winter season. Using the POLSAR data acquired over an instrumented area in the region of French Alps, we analyse the derived polarimetric parameters with respect to the network of simultaneous in situ snow pack measurements. The principal particularity of the presented analysis is the postprocessing of original polarimetric parameters, based on the Principal Component Analysis (PCA). Having a focus set on the dry snow depth retrieval, we compare these, derived polarimetric parameters with the in situ measured snow depth. The most significant observation is the strong inverse correlation between the depth of the snow above the first ice layer and the entropy. Motivated by a very high coefficient of determination of the performed linear regression $\left(R^{2}=0.8439\right)$, we propose in this article a physical hypothesis which appropriately relates the entropy and the snow depth.

\section{METHODOLOGY}

Total backscattering of the snow pack as a distributed target can be decomposed as the sum of the four following components [4] (Fig. 1):

1. Snow pack surface component,

2. Snow volume component, 


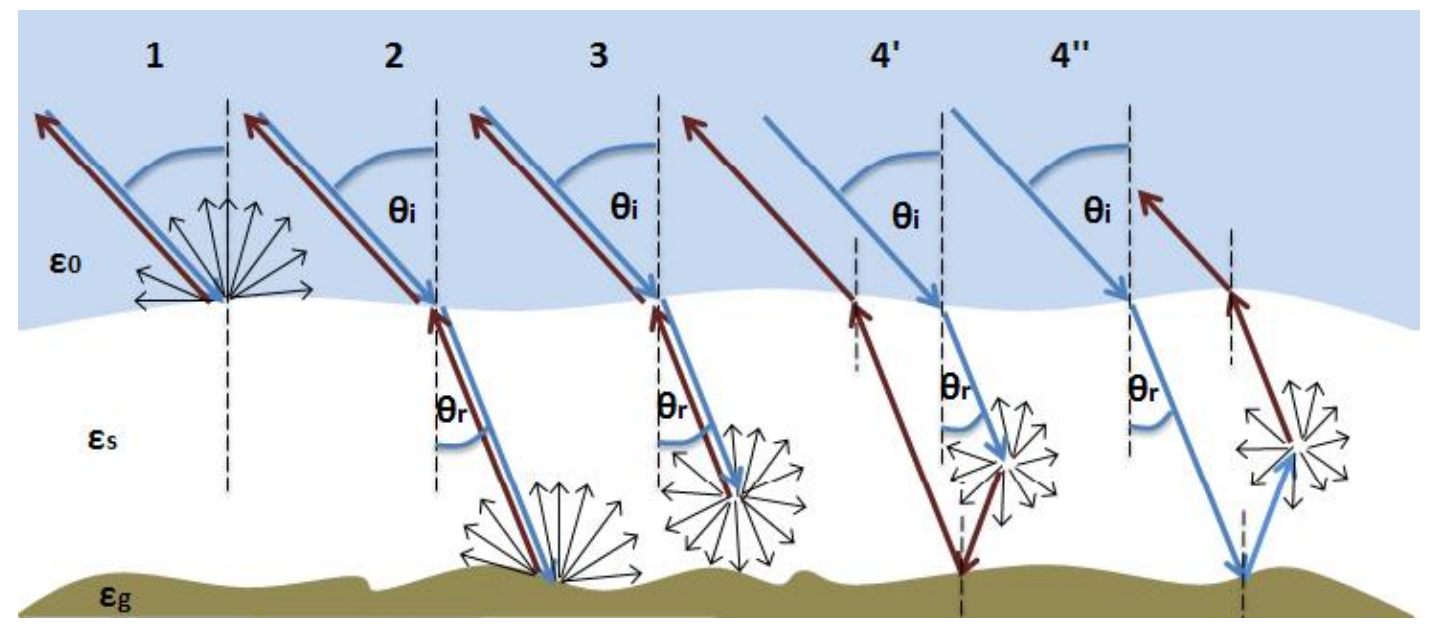

Fig. 1. Snow backscattering mechanism

\section{Underlying ground surface component,}

4. Ground volume interaction component.

At $\mathrm{C}$ band, we can observe a dominance of the snow surface component (1), in case of wet snow, and a dominance of the underlying ground component (3) in case of dry snow [5]. The sensitivity of the polarimetric measurements acquired by RADARSAT- 2 could help to retrieve the components (2) and (4), under certain conditions.

It has been demonstrated that relevant polarimetric parameters such as mean alpha angle $(\alpha)$ and entropy $(H)$ can be extracted from the eigenvalue-eigenvector decomposition of the coherency matrix $T$, and efficiently used to characterize the scattering properties of natural media [9, 7, 8]. The $\alpha$ angle is the main identification parameter for the nature of the mean scattering mechanism: $\alpha=0^{\circ}$ for surface scattering, $45^{\circ}$ for volume scattering and $90^{\circ}$ for double bounce scattering. The entropy $H$ describes the random behaviour of the global scattering phenomenon. This is due to the fact that entropy does not describe a particular scattering mechanism, but rather characterizes the global scattering process. Indeed, in case of a pure target scattering, $H=0$. On the other side, if the scattering is characterized by several, equally influential, scattering mechanisms, then $H=1$. In our case study, we used the algebraic $H / \alpha$ decomposition, proposed by Cloude and Pottier in [6]. The polarimetric parameters are obtained using the referent PolSARPro toolbox [10].

Concerning the observed entropy sensibility versus dry snow depth, we propose the following hypothesis as a physical justification. At the considered frequency ( $f=$ $5.3 \mathrm{GHz}$ ), given the unavoidable presence of ice crust inside the snow pack due to the metamorphism of the snow during the winter season, the reflection of the layer of ice under a pack of dry fresh snow will dominate over the underlying ground backscattering. Generally, refreezing, by forming a snow crust, leads to a very strong volume scattering (large grains representing strong scatterers) [11]. However, if the ice crust (a continuous layer of ice) is formed, it should be rather associated with a strong surface scattering. The support for this conclusion was found in the literature dealing with the passive microwave sensing of a snow cover. Namely, the formation of the crust significantly decreases the measured emissivity, by decreasing the influence of the underlying layers, causing the latter to be ignored in the modelling [12].

Additionally, the inferior roughness of the ice crust surface should rather cause specular reflection of the incident electromagnetic waves than their scattering. This fact, along with the insignificance of the snow surface and volume backscattering components in case of the dry snow, indicates the dominance of the ground-volume interaction component.

As it is seen in Fig. 2, bigger depth of a snow layer (d) means bigger propagation distance (p) of the reflected electromagnetic wave, which is to be rescattered by the volume. This implies bigger probability of interaction with snow particles, therefore bigger probability of recovering the most dominant mechanism.

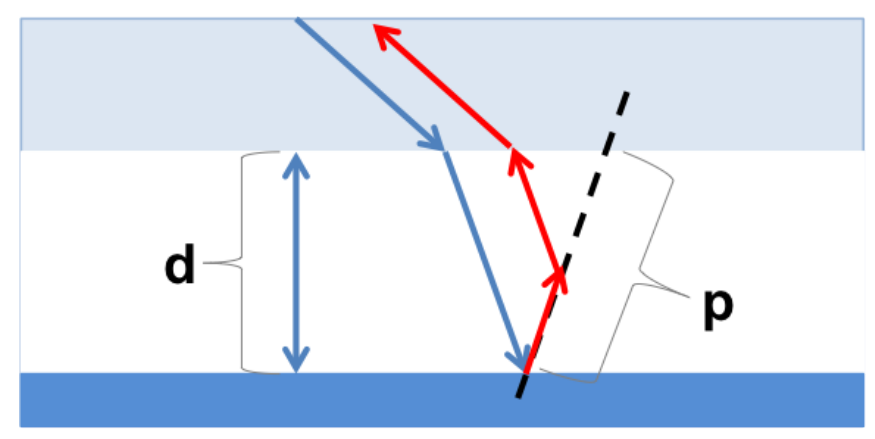

Fig. 2. Ground-volume interaction 


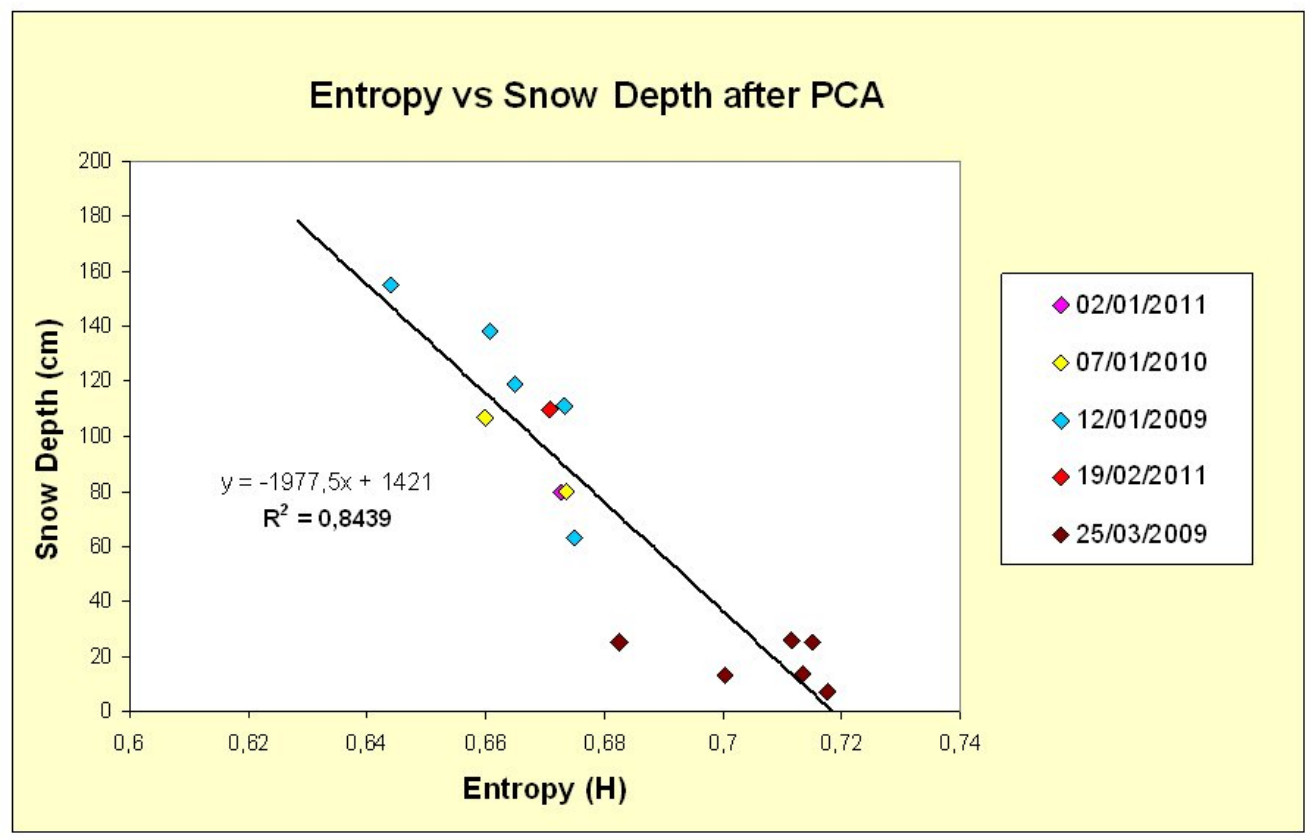

Fig. 3. Linear regression: entropy versus dry snow depth

The post-processing used in obtaining the analysed observations is based on the Principal Component Analysis (PCA). Namely, we created a covariance matrix including all the polarimetric parameters versus the target sites of the study, for all dates of images registration. The PCA process was set to reduce the signal noise of the composite components inferring on the polarimetric values (grain size, density, multiple layers). Thus, the data are reorganized using new reference axes where the first component of statistical weight appears to be the major explanatory factor between the physical parameters of the snow pack and the polarimetric descriptors. Then, a correlation table with the snowfield ground measurements was created for the statistical correlation results of the snow depth versus polarimetry.

\section{APPLICATION CASE AND RESULTS}

The study area is located in the northern French Alps $\left(45^{\circ} 09^{\prime}\right.$ $\left.\mathrm{N}, 6^{\circ} 10^{\prime} \mathrm{E}\right)$, close to the town of Grenoble. This high mountainous region is part of a $1200 \mathrm{~km}^{2}$ watershed equipped for hydro-power generation (Électricité de France (EDF), Grenoble) and instrumented by Météo France for avalanches and meteorological forecasting. The RADARSAT-2 imaging mode selected was fine quad-polarization (full polarimetry): swath width $25 \times 28 \mathrm{~km}$, Beam FQ19 in single look complex (SLC) mode for sampled pixels. Ground range by azimuth resolution was $7.51 \times 4.73 \mathrm{~m}$. Descending orbits (5:42 UT) with right looking direction were selected to be phased with the ground measurements at representative test sites (snow stratigraphy), together with data from EDF and Météo France automatic snow station networks. In regard of the high mountain environment, incidence angle of $39.6^{\circ}$ was selected for the beam configuration. A total of 10 winter images were registered from 2009 to 2011 and 5 dates of dominant dry snow conditions were selected for the study, including 15 sites of depth measurements, located in flat areas. All dry snow depth values measured concern only the section of the snow pack between the air surface (no wetness) and the underlying ground, or the first consistent layer of refrozen snow (solid crust).

\section{RESULTS}

After the PCA processing, the correlation table indicates a clear and strong relationship between snow depth measured above the first ice crust and the entropy $(H)$. It is an inverse correlation, being in accordance with the previously described, presumed backscattering physics (Fig. 2). The correlation results, obtained on 5 different dates, at 15 points, are very satisfying with a coefficient of determination for a deduced linear regression $R^{2}=0.8439$. Entropy values are ranking from 0.50 for large depths $(160$ to $180 \mathrm{~cm}$ ) expressing a relatively pure scattering, to 0.75 for smaller dry snow packs $(20$ to $40 \mathrm{~cm}$ ) reflecting more complex scattering process (Fig. 3). Fig. 4 describes the temporal evolution of the entropy parameter versus dry snow depth for a set of different sites and dates throughout the winter season (Julian days). Here, we can observe the increase of entropy as we approach the end of the winter season. Given that this temporal evolution is as well characterized by a decrease in dry snow depth, 


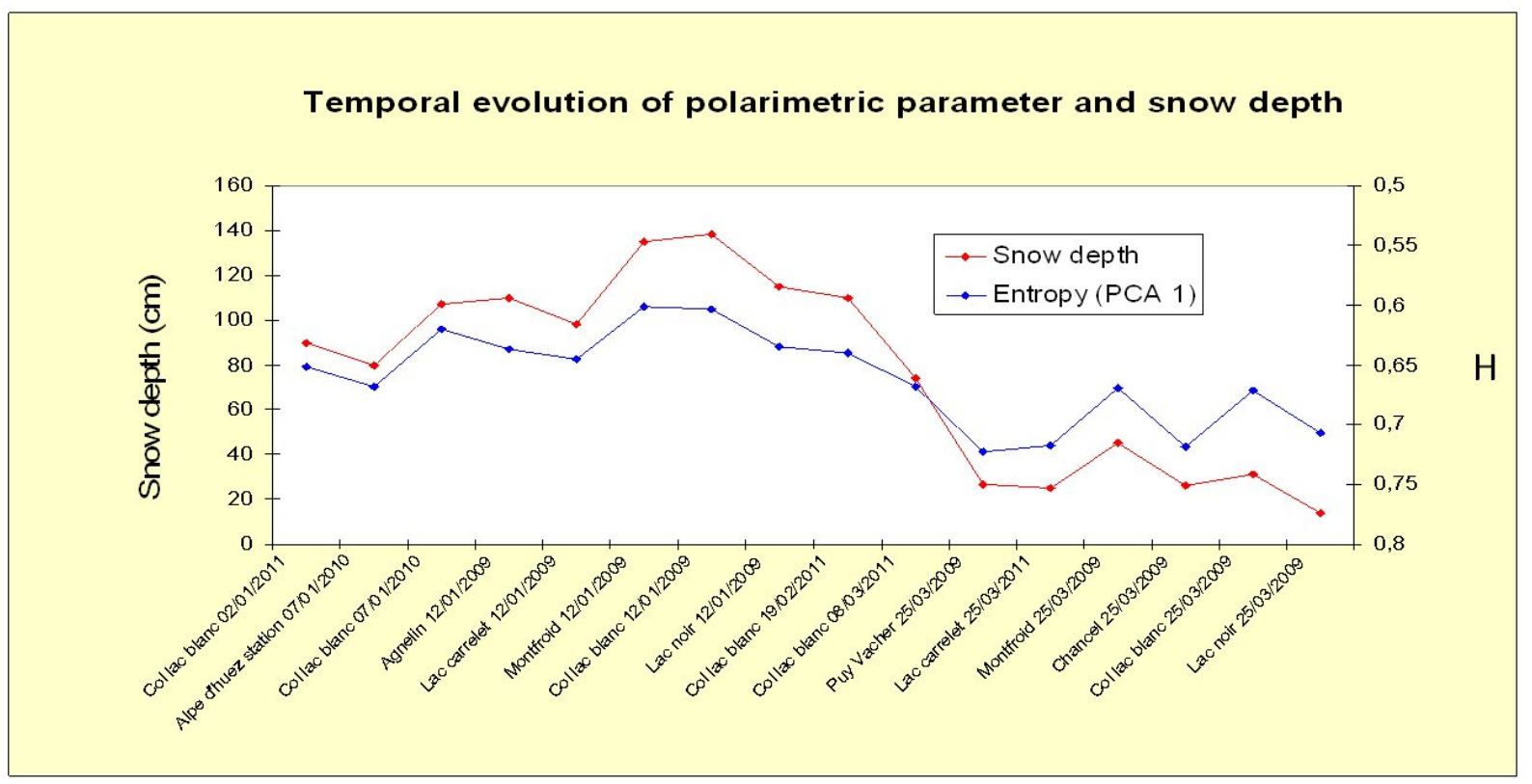

Fig. 4. Temporal evolution of the polarimetric parameter and the dry snow depth

the former assessment is reinforced.

\section{CONCLUSION}

In the French Alps, snow cover is one of the most important components in the run-off modelling and the snowmelt accounts for $50 \%$ of the annual stream flow (Rhone river). Snow water equivalent (SWE) characterise the snow pack, as a function of density and depth. Under dry snow conditions, the depth estimation of the snow pack retrieved from the full polarimetry RADARSAT- 2 configuration, merged with density network measurements, could offer a precious help for the SWE calculation at the large scale. With a big number of interrelated variables retrieved by the polarimetric decomposition, we observe that the PCA based post-processing of the POLSAR data can reduce the dimensionality of the data set and extract the most important polarimetric information, related to the physical properties of the target. In our case, the entropy parameter seems to be an efficient tool linked to the dry snow depth measurements. Namely, we observed an inverse correlation between the derived entropy and the snow depth above the first strong ice layer. This behaviour was appropriately physically justified.

\section{REFERENCES}

[1] A.K. Fung and M.F. Chen, "Modeling of microwave emission and scattering from snow and soil," Advanced Space Research, vol. 9, no. 1, pp. 297-306, 1989.

[2] Fawwaz T. Ulaby, W. Herschel Stiles, and Mohamed AbdelRazik, "Snowcover influence on backscattering from terrain," IEEE Trans. Geosci. Remote Sens., vol. GE-22, no. 2, pp. 126 -133, march 1984.
[3] A. Martini, L. Ferro-Famil, E. Pottier, and J.P. Dedieu, "Dry snow discrimination in alpine areas from multifrequency and multi-temporal sar data," IEE Sonar and Navigation, vol. 153, no. 3, pp. 271-278, 2006.

[4] N. Besic, G. Vasile, J. Chanussot, S. Stankovic, J.-P. Dedieu, G. dUrso, D. Boldo, and J.-P. Ovarlez, "Dry snow backscattering sensitivity on density change for swe estimation," in Proc. IEEE International Geoscience and Remote Sensing Symposium (IGARSS'12), Munich, DE, 2012, pp. 4418-4421.

[5] N. Besic, G. Vasile, J. Chanussot, S. Stankovic, J.-P. Ovarlez, G. dUrso, D. Boldo, and J.-P. Dedieu, "Stochastically based wet snow mapping with sar data," in Proc. IEEE International Geoscience and Remote Sensing Symposium (IGARSS'12), Munich, DE, 2012, pp. 4859-48621.

[6] S. R. Cloude and E. Pottier, "An entropy based classification scheme for land applications of polarimetric sar," IEEE Transactions on Geoscience and Remote Sensing, vol. 35, no. 1, pp. 68-78, 1997.

[7] L. Ferro-Famil, E. Pottier, and J.S. Lee, "Unsupervised classification of multifrequency and fully polarimetric sar images based on the $\mathrm{h} / \mathrm{a} / \alpha$ wishart classifier," IEEE Transactions on Geoscience and Remote Sensing, vol. 39, no. 1, pp. 2332-2342, 2001.

[8] J.S. Lee and E. Pottier, Polarimetric Radar Imaging: from basics to applications, CRC Press, Taylor and Francis Group, Boca Raton, FL, USA, 1st edition, 2009.

[9] S. R. Cloude and E. Pottier, "A review of target decomposition theorems in radar polarimetry," IEEE Transactions on Geoscience and Remote Sensing, vol. 34, no. 2, pp. 498-518, 1996.

[10] Dedieu J. P., G. Beninca de Farias, T. Castaings, S. Allain-Bailhache, E. Pottier, Y. Durand, and Bernier M., "Interpretation of a radarsat-2 fully polarimetric time series for snow cover studies in an alpine context," Canadian Journal of Remote Sensing, vol. 38, no. 3, pp. 336-351, 2012.

[11] T. Strozzi and C. Matzler, "Backscattering measurements of alpine snowcovers at 5.3 and $35 \mathrm{ghz}$," IEEE Trans. Geosci. Remote Sens., vol. 36, no. 3, pp. 838-848, 1998.

[12] C. Matzler and A. Wiesmann, "Extension of the microwave emission model of layered snowpacks to coarse-grained snow," Remote Sensing of Environment, vol. 70, no. 3, pp. 317 - 325, 1999. 